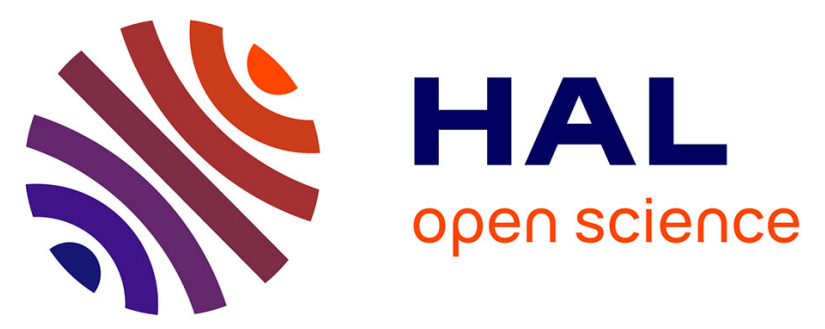

\title{
LDL-apheresis to decrease sFlt-1 during early severe preeclampsia: Report of two cases from a discontinued phase II trial
}

\author{
Bassam Haddad, Guillaume Lefèvre, Alexandra Rousseau, Thomas Robert, \\ Samir Saheb, Cédric Rafat, Marie Bornes, Camille Petit-Hoang, Frédéric \\ Richard, Edouard Lecarpentier, et al.
}

\section{To cite this version:}

Bassam Haddad, Guillaume Lefèvre, Alexandra Rousseau, Thomas Robert, Samir Saheb, et al.. LDLapheresis to decrease sFlt-1 during early severe preeclampsia: Report of two cases from a discontinued phase II trial. European Journal of Obstetrics \& Gynecology and Reproductive Biology, 2018, 231, pp.70-74. 10.1016/j.ejogrb.2018.09.009 . hal-01950261

\section{HAL Id: hal-01950261 \\ https://hal.sorbonne-universite.fr/hal-01950261}

Submitted on 10 Dec 2018

HAL is a multi-disciplinary open access archive for the deposit and dissemination of scientific research documents, whether they are published or not. The documents may come from teaching and research institutions in France or abroad, or from public or private research centers.
L'archive ouverte pluridisciplinaire HAL, est destinée au dépôt et à la diffusion de documents scientifiques de niveau recherche, publiés ou non, émanant des établissements d'enseignement et de recherche français ou étrangers, des laboratoires publics ou privés. 


\title{
LDL-apheresis to decrease sFlt-1 during early severe preeclampsia: Report of two cases from a discontinued phase II trial
}

\author{
Bassam Haddad ${ }^{\mathrm{a}}$, Guillaume Lefèvre ${ }^{\mathrm{b}}$, Alexandra Rousseau ${ }^{\mathrm{c}}$, Thomas Robert $^{\mathrm{d}}$, \\ Samir Saheb ${ }^{\mathrm{e}}$, Cedric Rafat ${ }^{\mathrm{d}}$, Marie Bornes ${ }^{\mathrm{f}}$, Camille Petit-Hoang ${ }^{\mathrm{d}}$, Frédéric Richard ${ }^{\mathrm{f}}$, \\ Edouard Lecarpentier ${ }^{\mathrm{g}}$, Vassilis Tsatsaris ${ }^{\mathrm{g}}$, Jean Guibourdenche ${ }^{\mathrm{h}}$, Anthony Corchia ${ }^{\mathrm{d}}$, \\ Eric Rondeau ${ }^{\mathrm{d}, \mathrm{i}}$, Tabassome Simon ${ }^{\mathrm{i}}$, Alexandre Hertig ${ }^{\mathrm{d}, \mathrm{j}, *}$
}

${ }^{a}$ CHI Créteil, CRC CHI Créteil, University Paris Est Créteil, Department of Obstetrics and Gynecology, Centre Hospitalier Intercommunal de Créteil, 40 Avenue de Verdun, 94000, Créteil, France

b AP-HP, Hôpital Tenon, Department of Biochemistry and Hormonology, Paris, F-75020, France

c APHP, Hôpital St Antoine, Plateforme de recherche Clinique de l'Est Parisien (URCEST-CRCEST), Paris, France

d APHP, Hôpital Tenon, Urgences Néphrologiques et Transplantation Rénale, Paris, France

e Groupe hospitalier La Pitié-Salpêtrière-Charles-Foix, Centre Clinique d'Hémobiothérapie, Service d'Hématologie, 75013, Paris, France

${ }^{\mathrm{f}}$ APHP, Hôpital Tenon, Department of Gynecology and Obstetrics, Paris, France

${ }^{\mathrm{g}}$ APHP, Hopital Cochin, Department of Gynecology and Obstetrics I, Paris, France

h APHP, Hopital Cochin, Biologie Hormonale, Paris, F-75006, France

${ }^{i}$ Sorbonne Universités, UPMC Université Paris 06, Department of Clinical Pharmacology, Paris, France

${ }^{\mathrm{j}}$ Sorbonne Universités, APHP, Hôpital Tenon, F-75020, Paris, France

Keywords:

Preeclampsia

Hypertension

LDL-apheresis

sFlt-1

\begin{abstract}
A B S T R A C T
Objective: Severe preeclampsia may require the delivery of the placenta to avoid life-threatening complications for the mother. Before 26 weeks of gestation, this often results in perinatal death. A decrease in soluble fms-like tyrosine kinase 1 (sFlt1), an anti-angiogenic factor central to the pathophysiology of the maternal syndrome, has been reported after LDL- apheresis. The present study tested whether LDL-apheresis could be used to allow women with early and severe preeclampsia to reach a gestational age where the baby had a viable chance of survival.

Study Design: A phase II prospective study. Adult women were included if they had very early ( $<26$ weeks of gestation) preeclampsia without severe ( $<5$ th percentile) intra-uterine growth retardation. Treatment consisted of two weekly sessions ( $90 \mathrm{~min}$ each) of LDL-apheresis of whole blood. The primary endpoint was the status of the baby (dead or living) at 6 months post-delivery. Sample size and stopping rules were calculated assuming a desired success rate of at least $90 \%$.

Results: The study was interrupted for safety reasons after the inclusion of two patients: both developed secondary uncontrolled hypertension and blurred vision during the first week of treatment. The first neonate, born at $25+3$ weeks of gestation, died of sepsis at day 5; the second, born at $26+2$ weeks of gestation, is still alive and well. In these two patients, the impact of apheresis sessions on sFlt1 concentrations was inconsistent.

Conclusion: LDL-apheresis did not result in the prolongation of pregnancy in this phase II trial. Further studies will be needed to delineate the appropriate contours of this therapeutic strategy.
\end{abstract}

Abbreviations: ACD, acid citrate dextrose; sFlt1, soluble form of fms-like tyrosine kinase 1; PlGF, Placental Growth Factor; RI, resistive index.

* Corresponding author at: UNTR, Hôpital Tenon, 4 rue de la Chine, 75020, Paris, France.

E-mail address: alexandre.hertig@sorbonne-universite.fr (A. Hertig).

\section{Introduction}

In high income countries, and in the context of preeclampsia, chances of survival to delivery and post-natal care are low if pregnancy does not go beyond 26 weeks of gestation [1]. Hence, if there is no immediate risk to the pregnant mother, the inclination of obstetricians and pediatricians in any pathological situation is not to intervene but be prepared to do so if necessary. Preeclampsia 
is emblematic of this dilemma, where the mother carries a placenta producing high amounts of anti-angiogenic factors, able to induce clinically severe endothelial dysfunction in the kidney, the liver, the brain and the lungs from 20 weeks of gestation onwards [2-6]. Among these anti-angiogenic factors, soluble Fmslike tyrosine kinase 1 (sFlt1) plays a key role in the renal phenotype (proteinuria and glomerular endotheliosis) and, most probably, in the morbid increase in blood pressure [3,7-9]. Demonstration of causality however requires that the syndrome be attenuated by sFlt1 removal or reduction. In this regard, a report published in 2011 that LDL-apheresis columns could decrease sFlt1 ex vivo in amniotic fluid, and in vivo in three preeclamptic patients, was a milestone in the race for a cure for preeclampsia [10]. This pilot study was consolidated by more recent data [11], providing convincing evidence that placental delivery could be delayed by days or weeks, at the cost of apheresis sessions that are reputedly safe outside the context of preeclampsia. The objective of our study was to test the hypothesis that LDL-apheresis sessions could allow the prolongation of pregnancy without threatening maternal survival in women presenting with very early $(<26$ weeks of gestation) and severe preeclampsia, and prolong it up to a point where the baby would survive (National Clinical Trials number was NCT\#02286284).

\section{Patients and methods}

\section{Inclusion criteria}

This phase II prospective trial was conducted between January 2015 and September 2015. Women were included if they were $\geq 18$ years old and had severe preeclampsia diagnosed between 23 and 25 weeks of gestation +6 days. Gestational age was defined using the last menstrual period as the origin of pregnancy, and confirmed by an early ultrasound. Severe preeclampsia was defined by the presence of at least one of the following criteria: systolic blood pressure $\geq 160 \mathrm{~mm} \mathrm{Hg}$ and/or diastolic blood pressure $\geq 110 \mathrm{~mm}$ $\mathrm{Hg}$; proteinuria > $5 \mathrm{~g}$ /day; visual disturbances; hyperreflexia; platelet count $<100 \mathrm{~g} / \mathrm{L}$ in the absence of HELLP syndrome. Noninclusion criteria were intrauterine growth retardation $<5$ th percentile (due to an exceptionally high chance of death at this early term of gestation), signs of fetal hypoxia on fetal cardiac rhythm, or any maternal condition, including eclampsia or persisting headaches, HELLP syndrome or any indication of elevated liver enzymes, pulmonary edema, acute kidney injury, sub-capsular hematoma of the liver, or placenta abruptio.

\section{Endpoints}

The primary endpoint was success rate, defined as the percentage of babies discharged alive (or still alive at 6 months if hospitalized). Secondary endpoints were: the time elapsed between inclusion and delivery; the incidence of severe complications of preeclampsia; incidence and severity of side effects attributable to the prescription of LDL- apheresis (related to venous catheterization, and to the procedure itself); the efficacy of sFlt1 removal from maternal serum; the length of stay of the baby in a neonatology unit; all-cause morbidity of the surviving children.

\section{LDL-apheresis}

Treatment consisted of two weekly sessions (90 min each). On the day of inclusion, a central venous catheter was inserted in the left jugular vein under local anesthesia by a vascular surgeon in the operating ward. Our extracorporeal apheresis protocol included a whole blood extracorporeal circulation (venovenous procedure) using a LDL-apheresis monitor (4008 ADS/Art hemoadsorption unit, Fresenius, Munchen, Germany) which deployed a DALI adsorber column (DALI 750, Fresenius, Munchen, Germany), consisting of polyacrylate ligands immobilized on a polyacrylamide matrix. This column had been successfully used long-term before, during, and after the pregnancy of a woman with hypercholesterolemia showing a mean $18 \%$ decrease (data not shown).

Prior to treatment, the extracorporeal circuit was flushed with 3 compartments of $2000 \mathrm{~mL}$ rinsing fluid (DALI set solution containing $\mathrm{Na}^{+} 134 \mathrm{mmol} / \mathrm{L}, \mathrm{K}^{+} 4.0 \mathrm{mmol} / \mathrm{L} \mathrm{Ca}^{2+} 1.75 \mathrm{mmol} / \mathrm{L} \mathrm{Mg}^{2}$ ${ }^{+} 0.5 \mathrm{mmol} / \mathrm{L}, \mathrm{Cl}^{-} 108.5 \mathrm{mmol} / \mathrm{L}$, and $\mathrm{HCO}_{3}{ }^{-} 36 \mathrm{mmol} / \mathrm{L}$; Fresenius, Munchen, Germany). For the first patient (as well as for the pregnant patient with hypercholesterolemia), the rinsing procedure also contained $20000 \mathrm{UI}$ of heparin to prevent clotting of extracorporeal circulation. However, based on the unfavorable clinical outcome of Patient \#1, and on the possible interference of heparin with sFlt1 removal due to its high density in negative charges [12] we decided to omit the heparin procedure for Patient \#2. During the sessions performed in both patients, anticoagulation treatment was delivered through the arterial line inlet, using an initial citrate solution/blood ratio of $1 / 20$ ( $1 \mathrm{~mL}$ of acid citrate dextrose (ACD)-A per $20 \mathrm{~mL}$ of blood), progressively decreasing to $1 / 50$ by the end of the session. Effective blood flow (QB) rate was $20 \mathrm{~mL} / \mathrm{min}$ for the first minute and was progressively increased to a maximum of $80 \mathrm{~mL} / \mathrm{min}$. Calculation of the blood volume treatment was assessed using the Nadler formula [13]. Duration of each session was less than $90 \mathrm{~min}$ to avoid bradykinin accumulation [14]. To avoid hypotension at initiation, $250 \mathrm{~mL}$ of isotonic saline solute was systematically infused.

\section{Angiogenic factors assays}

Blood samples were collected at the end of each LDL-apheresis session. Serum samples were collected. After clotting, samples were centrifuged at 3500 r.p.m. for $10 \mathrm{~min}$. Serum was stored at $-80^{\circ} \mathrm{C}$ for no longer than 1 month prior to analysis. sFlt- 1 and Placental growth factor (PIGF) were eventually assayed with 3 different immunoassays because values were unexpectedly high, raising the issue of test linearity: i) manual assay (Quantikine R\&D systems, Abingdon, UK); ii) on fully automated Kryptor Compact Plus (BRAHMS Thermo Fisher Scientifics, Henningsdorf, Germany) and iii) on fully automated Modular Analytics E 170 (Roche Diagnostics) analyzers. All assays were realized according to the manufacturer's instructions. For BRAHMS sFlt-1 (BRAHMS sFlt1 Kryptor) and PIGF assays (BRAHMS PIGF Plus Kryptor), the minimum detectable concentrations were $12 \mathrm{pg} / \mathrm{mL}$ and $3.6 \mathrm{pg} /$ $\mathrm{mL}$, respectively. Test linearity of sFlt 1 was found in the range $0-$ $90.000 \mathrm{pg} / \mathrm{mL}$. Test linearity of BRAHMS PIGF was found in the range $0-7.000 \mathrm{pg} / \mathrm{mL}$. For serum sFlt-1, the intra-assay and interassay coefficients of variation were less than $1 \%$ and $5 \%$, respectively. For serum PIGF, the intra-assay and inter-assay coefficients of variation were less than $8 \%$ and $10 \%$, respectively, according to the manufacturer's data. In our laboratory, BRAHMS sFlt1 and PIGF precisions (quality control inter-assay) were $1.5 \%$ and $5 \%$, respectively. For Roche sFlt- 1 and PIGF assays, the minimal detectable concentrations were 15 and $10 \mathrm{pg} / \mathrm{mL}$, respectively. Test linearity of Roche sFlt1 was found in the range $0-130.000 \mathrm{pg} / \mathrm{mL}$. Test linearity of Roche PIGF was found in the range $0-10.000 \mathrm{pg} / \mathrm{mL}$. The intra-assay and inter-assay coefficients of variation for serum sFlt- 1 were $0.5-6.8 \%$ and $0.7-11 \%$, respectively; the intra-assay and inter-assay coefficients of variation for serum PIGF were $0.6-2.6 \%$ and $0.6-5.9 \%$, respectively, according to the manufacturer's data. By default, Kryptor data are provided in the text. 


\section{Ethical evaluation}

All the patients provided written informed consent. The study was approved by the ethical committee "Comité de Protection des Personnes Ile de France IV" and by the French National Agency for Medicines and Health Products Safety (ANSM).

\section{Study design and statistics}

This phase II trial was planned using a Simon's Minimax twostage design. At the first stage, a sample size of 8 patients was required. If the number of success was $\leq 5$, the study had to be terminated for a lack of efficacy. Otherwise, 9 more patients were to be recruited to lead to an overall sample size of 17 patients. If the total number of success was $\leq 13$ then the study had to be stopped and we would conclude a lack of efficacy of the LDL-apheresis. If not, LDL-apheresis could be considered as sufficiently promising for a larger confirmatory phase III trial. Sample size and stopping rules were calculated assuming a desired success rate of at least $90 \%$ (P1) and no further interest in the LDL-apheresis if the success rate was less than $60 \%(\mathrm{P0})$, alpha $=5 \%$ and beta $=10 \%$. The average sample size (EN(P0)) was 10.8 and probability of early termination after the first stage (PET(P0)) was 0.68. In view of the number of patients actually recruited, we provide only descriptive data.

\section{Role of the independent surveillance committee}

Since this study was designed to include patients at high risk of morbidity, and of very premature delivery, it had been decided that an independent surveillance committee would determine whether the study should be continued or terminated after each inclusion. This committee was composed of an obstetrician, a perinatalogist, and a physician specializing in apheresis (see Acknowledgments).

\section{Results}

Two patients were included from March to July 2015. Inclusions were suspended in September 2015, and early termination of the study was decided by the sponsor in November 2015, on the recommendation of the independent surveillance committee, because of the futility of the procedure. Absence of durable clinical efficacy was the main driver behind this difficult decision, but the failure to decrease sFlt-1 concentration in these patients with severe preeclampsia and very high concentrations of sFlt-1 in maternal blood, endorsed the decision.

\section{PE patient \#1}

Patient \#1 was a 37-year-old gravida 1 para 0 woman with a single fetus. She had a history of hypertension, HIV infection, depression and cervical conization. She was an active smoker before and during pregnancy. She received no anti-hypertensive drugs, and had no detectable albuminuria on dipsticks tested early in pregnancy. Hypertension was observed at $19+6$ weeks of gestation $(140 / 100 \mathrm{mmHg})$ and a bilateral notch was recorded on the uterine Doppler with a resistive index (RI) of 0.7 at $22+5$ weeks of gestation. The patient started oral nicardipine at $23+6$ weeks of gestation. Blood pressure increased sharply at $24+4$ weeks of gestation $(190 / 120 \mathrm{mmHg})$ accompanied by headache, myodesopsia and photophobia. Physical examination found pedal edema and hyperreflexia. Laboratory findings were normal, except for urine protein-to-creatinine ratio $(1.06 \mathrm{~g} / \mathrm{mmol})$. She was admitted to hospital and continuous intravenous nicardipine initiated, plus labetalol a few hours later, with betamethasone (at $24+4$ and $24+5$ weeks of gestation). Fetal weight was estimated by ultrasound at $640 \mathrm{~g}$ (35th percentile). RI was 0.89 on umbilical
Doppler, and a bilateral notch was detected, with RIs of 0.68 and 0.70 on uterine Doppler. Fetal heart rate was $130 \mathrm{bpm}$ with no signs of deceleration. Proteinuria had decreased to $0.49 \mathrm{~g} / \mathrm{mmol}$ after blood pressure medication. The patient was transferred at $24+6$ weeks of gestation to our center. At inclusion, blood pressure was $170 / 99 \mathrm{mmHg}$. The patient presented with mild headache and tinnitus. Clinical examination found hyperreflexia and generalized edema. Laboratory findings were normal except for mild anemia (hemoglobin $9.7 \mathrm{~g} / \mathrm{dL}$ ), and elevated sFlt-1 levels at $17,650 \mathrm{pg} / \mathrm{mL}$ (sFlt1/PlGF ratio was 1858). The first session of apheresis occurred at day 0 of inclusion ( $24+6$ weeks of gestation), and lasted $112 \mathrm{~min}$, during which time $4650 \mathrm{~mL}$ of whole blood were treated. Blood pressure had dropped from $162 / 96$ to $130 / 82 \mathrm{mmHg}$. Labetalol was decreased from 16 to $10 \mathrm{mg} / \mathrm{h}$ during the session and proteinuria was stable at $0.48 \mathrm{~g} / \mathrm{mmol}$ creatinine. The patient also reported an improvement in headache and blurred vision. Concentration of sFlt1 before and after the LDL session is shown in Table 1. Surprisingly, sFlt1 concentration increased following the session. PlGF increased from 9.5 to $160 \mathrm{pg} / \mathrm{mL}$. The sFlt-1:PIGF ratio was exceptionally high (at this stage of pregnancy range it would be expected to be 50(6)) and decreased from 4931 to 794 . Soluble endoglin concentration decreased from 164 to $128 \mathrm{ng} / \mathrm{mL}$. LDL cholesterol decreased from 4.12 to $1.23 \mathrm{mmol} / \mathrm{L}$, and fibrinogen decreased from 3.6 to $2.91 \mathrm{~g} / \mathrm{L}$. At day 1 blood pressure was controlled but headache and blurred vision increased again, and hyperreflexia was obvious. Magnesium sulfate $(1 \mathrm{~g} / \mathrm{h})$ was initiated. At day $2(25+1$ weeks of gestation), edema worsened $(+3 \mathrm{~kg})$. Urine-to-creatinine ratio rose to $0.6 \mathrm{~g} / \mathrm{mmol}$. The decision was taken to terminate the pregnancy. The patient had mild pulmonary edema and was transferred to the maternity unit. A cesarean section was performed to deliver a girl weighing $550 \mathrm{~g}$ (10th percentile). Apgar scores were 8/5/9/10. Maternal blood pressure remained elevated after delivery, requiring increasing doses of labetalol (up to $36 \mathrm{mg} / \mathrm{h}$ ). It was eventually discontinued at day 8 . Proteinuria dropped to $1.92 \mathrm{~g} / 24 \mathrm{~h}, 4$ days after delivery, and blood pressure was $133 / 78 \mathrm{mmHg}$ at day 9 . The patient refused further follow-up. The newborn required immediate oral intubation due to hyaline membrane disease. She died at 5 days old from early nosocomial infection due to septic shock and multi-organ failure.

\section{PE patient \#2}

Patient \#2 was a 26-year-old gravida 2 para 0 woman with a single fetus. She had no medical history, no chronic hypertension and no diabetes mellitus. She was a non-smoker. She presented to her general practitioner with hypertension and proteinuria at $23+6$ weeks of gestation. Blood pressure was $160 / 100 \mathrm{mmHg}$ and urine dipstick yielded $1+$ proteinuria. Two days later at $24+2$ weeks of gestation, she developed headache with persistent hypertension. Nicardipine was administered intravenously by

Table 1

Concentrations of sFlt1 in maternal serum.

\begin{tabular}{llllll}
\hline & & & \multicolumn{2}{c}{ sFlt1 (pg/mL) } \\
\cline { 3 - 5 } & & & Kryptor & Roche \\
\hline Patient \#1 & March 12, 3.30 pm & Before session \#1 & 17,650 & 18458 \\
& March 12, 5.12 pm & After session \#1 & 74095 & 96160 \\
& March 17, 3 pm & Post delivery & 16840 & 31055 \\
& & & & \\
Patient \#2 & July 6, 3.40 pm & Before session \#1 & 14,070 & 14404 \\
& July 7, 5 pm & Before session \#1 & 11460 & 12477 \\
& July 7, 5.30 pm & After 30 min of apheresis & 30120 & 37770 \\
& July 7, 6.20 pm & After 80 min of apheresis & 21250 & 8065 \\
& July 7, 6.30 pm & After session \#1 & 21840 & 10904 \\
& July 9, 5.45 pm & Before session \#2 & 11370 & 12421 \\
& July 7, 7 pm & After session \#2 & 20870 & 11593 \\
\hline
\end{tabular}


continuous infusion. She also received two doses of betamethasone. Estimated fetal weight was $665 \mathrm{~g}$ which was at the 50th percentile for gestational age. Umbilical and cerebral artery Doppler parameters were normal. Uterine Doppler demonstrated a bilateral positive notch. Fetal heart monitoring was normal. Laboratory findings were normal, except for $24 \mathrm{~h}$ proteinuria $(1.87 \mathrm{~g} / 24 \mathrm{~h})$. Although hypertension was controlled by oral nicardipine, proteinuria was $13.9 \mathrm{~g} / 24 \mathrm{~h}$ at $25+3$ weeks of gestation, meeting the criteria for severe preeclampsia. Fetal ultrasound showed an increase in umbilical RI at 0.83 and cerebral vasodilatation (RI 0.73). The patient was transferred at $25+5$ weeks of gestation to our center. At inclusion, blood pressure was $173 / 125 \mathrm{mmHg}$, there was a general edema, and proteinuria was $1.28 \mathrm{~g} / \mathrm{mmol}$. Blood pressure was decreased to $124 / 89 \mathrm{mmHg}$ by intravenous continuous infusion of nicardipine $(6 \mathrm{mg} / \mathrm{H})$, plus oral labetalol and methydopa. Laboratory findings were normal except for proteinuria $(1.38 \mathrm{~g} / \mathrm{mmol})$ and elevated sFlt-1 levels at $14,070 \mathrm{pg} / \mathrm{mL}$ (sFlt1/PIGF ratio was 1617). LDL-apheresis lasted $90 \mathrm{~min}$, during which $3.5 \mathrm{~L}$ of whole blood were treated. The session was well tolerated, except for local paresthesia attributed to mild hypocalcemia $(0.99 \mathrm{mmol} / \mathrm{L})$ during apheresis. Blood pressure rapidly improved after apheresis allowing the cessation of intravenous nicardipine and oral methyldopa at day 2. Likewise, urine protein-to-creatinine ratio dropped by $84.6 \%$ to $0.21 \mathrm{~g} / \mathrm{mmol}$. LDL cholesterol decreased from 4.28 to $2.34 \mathrm{mmol} / \mathrm{L}$, and fibrinogen decreased from 3.65 to $2.71 \mathrm{~g} / \mathrm{L}$.

On day 3, blood pressure rose again to $152 / 114 \mathrm{mmHg}$, and continuous intravenous nicardipine was resumed $(0.5 \mathrm{mg} / \mathrm{h})$. A second session of apheresis was performed, also well tolerated; $2.82 \mathrm{~L}$ of whole blood were treated for a period of $45 \mathrm{~min}$. LDL cholesterol decreased from 3.1 to $1.71 \mathrm{mmol} / \mathrm{L}$, and fibrinogen decreased from 2.75 to $2.23 \mathrm{~g} / \mathrm{L}$. Blood pressure remained elevated $(176 / 119 \mathrm{mmHg})$. Hyperreflexia, headache and blurred vision were noted. Laboratory findings showed a magnesium concentration within the normal range $(0.72 \mathrm{mmol} / \mathrm{L})$, but a decrease in platelet $(-60.000 / \mathrm{mm}$ [3]) and hemoglobin $(-0.6 \mathrm{~g} / \mathrm{dL})$ count, plus an undetectable haptoglobinemia which, although liver enzymes were normal, suggested incident thrombotic microangiopathy. Intravenous magnesium sulfate $(3 \mathrm{~g}$ ) was given and the patient was transferred to the maternity ward. The next day, the patient presented with acute pulmonary edema, acute kidney injury and deterioration of coagulation tests. A cesarean section was performed at $26+2$ weeks of gestation. At delivery, the newborn girl weighed $630 \mathrm{~g}$. Apgar scores were 2/2/6/10. Maternal blood pressure decreased after delivery, to around $140 / 95 \mathrm{mmHg}$. Urine protein-to-creatinine ratio had dropped to $0.134 \mathrm{~g} / \mathrm{mmol}$ after one week. By 4 weeks, both hypertension and proteinuria had resolved. With regard to the newborn, there was severe respiratory distress at birth caused by hyaline membrane disease, which required oral intubation. She remained in a neonatal intensive care unit for 4 months due to severe prematurity. She is currently alive and healthy, except for a retinopathy of the left eye.

As in Patient \#1, LDL apheresis actually increased plasmatic level of sFlt-1 (Table 1). PIGF decreased from 8.7 to $8 \mathrm{pg} / \mathrm{mL}$ after the first session, and from 13.1 to $6.1 \mathrm{pg} / \mathrm{mL}$ after the second one. The sFlt-1:PIGF ratio was also exceptionally high, and decreased from 1801 to 189 , and from 1555 to 410 , during the first and second sessions, respectively. Soluble endoglin concentration decreased from 164 to $128 \mathrm{ng} / \mathrm{mL}$ after the first session and from 81 to $76 \mathrm{ng} /$ $\mathrm{mL}$ after the second one.

\section{Comment}

In contrast to the safety and efficacy of LDL-apheresis sessions performed in pregnant women with hypercholesterolemia but without preeclampsia, LDL-apheresis failed, in our study, to decrease sFlt1 concentration in maternal serum from two patients with early and severe preeclampsia. Despite a transient clinical improvement, both subjective and objective (reduced proteinuria, and reduced need for anti-hypertensive drugs during the first $36 \mathrm{~h}$ ), a sudden and uncontrollable increase in clinical symptoms rapidly led to a caesarean delivery in both preeclamptic patients. Overall, the independent surveillance committee recommended that the study should be terminated after the second inclusion, because of a lack of clinical efficacy, and of a lack of evidence that sFlt 1 was sufficiently decreased in this highly challenging context.

Importantly, the LDL-apheresis column we used in this trial is not the same as the one used in Germany and in the US. We used the DALI $^{\odot} 750$ columns, the principle of which is similarly based on negatively-charged dextrans, that will capture sFlt1 in a non specific way.

Heparin has been shown to induce a significant increase in sFlt1 concentrations during hemodialysis sessions (leading to $\mathrm{ng} / \mathrm{mL}$ ranges, despite the absence of pregnancy). The first patient we included was treated with a membrane which had been rinsed with a sodium chloride solution containing heparin, and we do not exclude the possibility that this somehow interfered with treatment efficacy.

A more striking difference between our study and the other two is the term and severity of preeclampsia at inclusion as illustrated by an exceptionally high sFlt1/PIGF ratio in our patients: ratios as high have been shown to be strongly indicative of an imminent delivery. Whether the columns were quickly saturated by enormous amounts of sFlt1 which thereby prevented any significant sFlt1 removal, or whether there was biological competition between other molecules (including LDL cholesterol) and sFlt1, would deserve further study.

A major limitation of our study is that only two patients were included. The independent surveillance committee in fact decided that these two patients provided sufficient data to stop the trial. Their decision was mostly based on the lack of evidence that sFlt 1 could be significantly decreased in patients fulfilling our inclusion criteria.

We are aware that our results are discouraging, and we do not cast into doubt previous studies: this trial was based on the assumption (verified here, during normal pregnancy) that sFlt1 would be decreased by LDL-apheresis and that this burdensome and costly technique would be especially appropriate for women in whom preeclampsia would - spontaneously - have tragic consequences. Whether these women, with unusually high sFlt1 concentrations, would benefit from a consistent decrease in sFlt1 concentration remains to be demonstrated. It is important to bear in mind that in the two positive trials previously published, sFlt-1 level returned to baseline shortly after apheresis. It is debatable whether such a transient decrease in sFlt- 1 is the best explanation for improved outcome, since many other factors, such as fibrinogen or complement proteins, are also decreased by this procedure. Interestingly, in this respect, a recent study reported that a positive outcome could be observed using heparin-mediated extracorporeal LDL precipitation, a technique which does not decrease sFlt1 concentration in maternal blood [15].

\section{Conclusion}

LDL-apheresis failed to decrease sFlt 1 concentration in maternal serum, and had no clinically significant impact on pregnancy outcome, in two patients with very early and severe preeclampsia. Whether other methods, specific or not, may have superiorefficacy in this particular context, will warrant other studies.

\section{Disclosures}

None 


\section{Funding}

This study was funded by grants from the Programme Hospitalier de Recherche Clinique Interrégional, French Ministry of Health (A0R13025). Fresenius Medical Care provided the apheresis material. L'association des amis de la maternité funded the transfer of patients to Tenon at the time of inclusion.

\section{Authorship}

$\mathrm{BH}$ and $\mathrm{AH}$ designed the study and wrote the manuscript. GL performed all the biological analysis and critically revised the manuscript. AR and TS designed the methodology. TR, SS, CR, MB, $\mathrm{CPH}, \mathrm{FR}, \mathrm{EL}, \mathrm{VT}, \mathrm{AC}$ and ER took care of the patients and critically commented on the manuscript. JG critically analyzed the biochemical data.

\section{Declaration}

The study was approved by the ethical committee "Ile de France IV" (2014/41) on January 29 2015.

\section{Acknowledgments}

The sponsor of the study was Assistance Publique-Hôpitaux de Paris (Département de la Recherche Clinique et du Développement, Clinical Research and Development Department). We are grateful to the two patients who agreed to enrollment in this study. We thank Marjolaine Rojano, for excellent technical expertise, and Elodie Papeloux-Heitzmann, psychologist, for her talented care of the patients. We would also like to thank the members of the independent surveillance committee, for fruitful discussions: Farhad Heshmati, MD at the Transfusion Medicine Unit of Hôpital Cochin, Pierre-Yves Ancel, MD, INSERM U-1153: Obstetrical, Perinatal and Pediatric Epidemiology Research, and Elie Azria, MD (Obstetric/Gynecology Department at Saint-Joseph Hospital in Paris). We thank Akim Souag and Florence Bayard-Lenoir who were project managers at the Clinical Research Department of APHP); Amel Touati, Carla Vandenabele, Florian d'Arco and Cynthia Dumoulin from the Clinical Research Unit of the East of Paris (URC-EST); Clinical Research Center of East of Paris (CRC-Est); Laetitia Beraud from the Department of Biochemistry of Tenon Hospital; Aude Fillette and Blandine Micouin (Pharmacy of Tenon) for their involvement during the study.

\section{Appendix A. Supplementary data}

Supplementary data associated with this article can be found, in the online version, at https://doi.org/10.1016/j.ejogrb.2018.09.009.

\section{References}

[1] Belghiti J., Kayem G, Tsatsaris V, Goffinet F, Sibai BM, Haddad B. Benefits and risks of expectant management of severe preeclampsia at less than 26 weeks gestation: the impact of gestational age and severe fetal growth restriction. Am J Obstet Gynecol 2011;205(November (5))465 e1-6.

[2] Mol BWJ, Roberts CT, Thangaratinam S, Magee LA, de Groot CJM, Hofmeyr GJ. Pre-eclampsia. Lancet Lond Engl 2015;2(September).

[3] Maynard SE, Min J-Y, Merchan J, Lim K-H, Li J, Mondal S, et al. Excess placental soluble fms-like tyrosine kinase 1 (sFlt1) may contribute to endothelial dysfunction, hypertension, and proteinuria in preeclampsia. J Clin Invest 2003;111(March (5)):649-58.

[4] Levine RJ, Maynard SE, Qian C, Lim K-H, England LJ, Yu KF, et al. Circulating angiogenic factors and the risk of preeclampsia. N Engl J Med 2004;350 (February (7)):672-83.

[5] Venkatesha S, Toporsian M, Lam C, Hanai J, Mammoto T, Kim YM, et al. Soluble endoglin contributes to the pathogenesis of preeclampsia. Nat Med 2006;12 (June (6)):642-9.

[6] Levine RJ, Lam C, Qian C, Yu KF, Maynard SE, Sachs BP, et al. Soluble endoglin and other circulating antiangiogenic factors in preeclampsia. N Engl J Med 2006;355(September (10)):992-1005.

[7] Luttun A, Carmeliet P. Soluble VEGF receptor Flt1: the elusive preeclampsia factor discovered? J Clin Invest 2003;111(March (5)):600-2.

[8] Eremina V, Sood M, Haigh J, Nagy A, Lajoie G, Ferrara N, et al. Glomerularspecific alterations of VEGF-A expression lead to distinct congenital and acquired renal diseases. J Clin Invest 2003;111(March (5)):707-16.

[9] Eremina V, Jefferson JA, Kowalewska J, Hochster H, Haas M, Weisstuch J, et al VEGF inhibition and renal thrombotic microangiopathy. N Engl J Med 2008;358(March (11):1129-36.

[10] Thadhani R, Kisner T, Hagmann H, Bossung V, Noack S, Schaarschmidt W, et al. Pilot study of extracorporeal removal of soluble fms-like tyrosine kinase 1 in preeclampsia. Circulation 2011;124(August (8)):940-50.

[11] Thadhani R, Hagmann H, Schaarschmidt W, Roth B, Cingoez T, Karumanchi SA et al. Removal of soluble fms-like tyrosine Kinase- 1 by dextran sulfate apheresis in Preeclampsia. J Am Soc Nephrol JASN. 2015;24(September)

[12] Lavainne F, Meffray E, Pepper RJ, Néel M, Delcroix C, Salama AD, et al. Heparin use during dialysis sessions induces an increase in the antiangiogenic factor soluble Flt1. Nephrol Dial Transplant Off Publ Eur Dial Transpl Assoc - Eur Ren Assoc. 2014;29(June(6)):1225-31.

[13] Nadler SB, Hidalgo JH, Bloch T. Prediction of blood volume in normal human adults. Surgery 1962;51(February (2)):224-32.

[14] Kojima S, Ogi M, Yoshitomi Y, Kuramochi M, Ikeda J, Naganawa M, et al. Changes in bradykinin and prostaglandins plasma levels during dextransulfate low-density-lipoprotein apheresis. Int J Artif Organs 1997;20(March (3)):178-83.

[15] Winkler K, Contini C, König B, Krumrey B, Pütz G, Zschiedrich S, et al. Treatment of very preterm preeclampsia via heparin-mediated extracorporeal LDL-precipitation (H.E.L.P.) apheresis: the Freiburg preeclampsia H.E.L.P.Apheresis study. Pregnancy Hypertens 2018;12(April):136-43. 